\title{
Fatty acid composition and sensory analysis in Boer kids meat
}

\author{
Angela Cividini', Ana Kaić² , Dragomir Kompan'1 and Klemen Potočnik ${ }^{1}$ \\ 'Department of Animal Science, Biotechnical Faculty, University of Ljubljana, Domžale, Slovenia, ${ }^{2}$ Department of \\ Animal Science and Technology, Faculty of Agriculture, University of Zagreb, Zagreb, Croatia
}

\begin{abstract}
This study was undertaken to characterize the fatty acid profile and sensory properties of longissimus dorsi (LD) muscle of Boer kids as affected by sex ( 17 male, 15 female) and slaughter weight (pre-weaned $20 \mathrm{~kg}$, post-weaned $30 \mathrm{~kg}$ ). Regarding sex differences, higher percentage amounts of lauric, myristic, pentadecanoic, linolenic and docosapentaenoic acids were found in LD muscle of male compared to female kids, whereas greater amounts of oleic acid were detected in LD muscle of female kids. Also, LD of male kids contained higher percentage amounts of saturated (SFA), polyunsaturated (PUFA) and $n-3$ polyunsaturated fatty acids ( $n-3$ PUFA) while higher amounts of monounsaturated fatty acids (MUFA) were detected in LD of female kids. Regarding slaughter weight, percentage amounts of lauric, myristic, margaric, pentadecanoic, linolenic, linoleic, arachidonic and docosapentaenoic acids significantly decreased with age $(P \leq 0.001)$, while percentage amounts of heptadecenoic and oleic acids significantly increased $(P \leq 0.001)$. LD muscle from lighter kids contained higher percentage amounts of SFA and PUFA, while heavier kids had higher percentage amounts of MUFA and $n-3 / n-6$ fatty acid ratio. Except meat colour, sensory traits (marbling, off-odour, flavour, juiciness and tenderness) were neither significantly affected by sex nor slaughter age.
\end{abstract}

Keywords: fatty acid composition, kids, sensory traits, sex

Abbreviations: LD: longissimus dorsi, MUFA: monosaturated fatty acids, ns: not significant, PUFA: polyunsaturated fatty acids, SFA: saturated fatty acids, UFA: unsaturated fatty acids

Archiv Tierzucht 57 (2014) 7, 1-9

doi: 10.7482/0003-9438-57-007
Received: 29 November 2013 Accepted: 17 March 2014 Online: 19 May 2014

Corresponding author:

Ana Kaić; email: akaic@agr.hr

Department of Animal Science and Technology, Faculty of Agriculture, University of Zagreb, Svetošimunska cesta 25, 10000 Zagreb, Croatia

() 2014 by the authors; licensee Leibniz Institute for Farm Animal Biology (FBN), Dummerstorf, Germany. This is an Open Access article distributed under the terms and conditions of the Creative Commons Attribution 3.0 License (http://creativecommons.org/licenses/by/3.0/). 


\section{Introduction}

In comparison to other meats available on the market, goat meat has advantages such as low fat, high digestibility, high protein, iron and unsaturated fatty acid amounts (Madruga 2004). Although consumption of goat meat varies according to the demands of the societies, consumer demands are more often in search of low-fat, low-calorie, healthy and a new meat sources (De Smet 2012). Previous studies have shown that consumers' perception on meat healthiness is related to its fat content and fatty acid composition (Fisher et al. 2000). Meat quality and acceptability is also affected by its appearance (colour), tenderness and sensory properties (Krystallis \& Arvanitoyannis 2006, Kor \& Keskin 2011). The sensory quality of meat remains one of the primary factors influencing consumer satisfaction (Kor \& Keskin 2011). Increasing consumer demands for goat meat has led to elevated consumers expectations towards goat meat quality and sensory characteristics. Due to fast grow rates and excellent carcass qualities of Boer goats, this study aimed at characterizing lipid profiles and sensory properties of Boer kids of different sex and slaughter weight.

\section{Material and methods}

\section{Animals and rearing}

The study was carried out at the Educational and Research Animal Husbandry Centre (Logatec) of Department of Animal Science at Biotechnical Faculty (University of Ljubljana, Slovenia). Thirty-two Boer genotype twin and triplet kids (17 male and 15 female kids) were used in the study. Kids were randomly assigned into two different groups based on target slaughter weight of 20 and $30 \mathrm{~kg}$. Each group represent both sexes. Kids stayed with their mothers until weaning at around $20 \mathrm{~kg}$ of live weight ( 85 days of age). All kids were weaned at the same time, when they reached around $20 \mathrm{~kg}$ (80-90 days of age). The first group (G1) comprised of eight male and eight female kids represents weaned kids slaughtered on weaning day at an average slaughter weight of $20 \mathrm{~kg}$ ( 85 days of age). The remaining kids (nine male and seven female; G2) after weaning, were fed on with hay and commercial concentrate (18\% crude protein, $2.2 \%$ crude fat, $7.9 \%$ crude fibre, $7.8 \%$ ash) until they reached $30 \mathrm{~kg}$ of slaughter weight (140 days of age). The kids were weighted once a week to follow the growth and slaughtered by the same procedure on consecutive dates when reached the predetermined slaughter weight. At slaughter, lambs were weighted on the farm before transportation to the experimental abattoir at the Zootechnical Department at Biotechnical Faculty $(50 \mathrm{~km})$. Carcasses were kept at $18^{\circ} \mathrm{C}$ for $5 \mathrm{~h}$ to avoid the development of cold shortening, and then chilled at $4^{\circ} \mathrm{C}$ for $24 \mathrm{~h}$ in a conventional chill cooler.

\section{Sampling}

The longissimus dorsi (LD) samples were taken $24 \mathrm{~h}$ post mortem from whole loin cuts. The LD samples for fatty acid analysis were cut between the last thoracic and first lumbar vertebrae and between the second and third lumbar vertebrae of each carcass $(100 \mathrm{~g})$ and were vacuum-packaged in polyamide - polyethylene bags and immediately stored at $-20^{\circ} \mathrm{C}$. The other half of the loin (cut between the second and third lumbar vertebrae and between the last lumbar and first sacral vertebrae) was used for sensory analysis. The samples for sensory 
analysis were vacuum-packaged into polyamide-polyethylene bags and stored at $-20^{\circ} \mathrm{C}$ after 3 days ageing at $4^{\circ} \mathrm{C}$. Before the analysis began samples were thawed overnight at $4{ }^{\circ} \mathrm{C}$.

\section{Fatty acid analysis}

Total intramuscular fat in LD muscle samples was analysed according to manufacturer's protocol (Foss, Application note). Briefly, meat samples were firstly hydrolysed in $4 \mathrm{M} \mathrm{HCl}$ and dried. In hydrolysed samples crude fat was determined by solvent extraction using petroleum ether $\left(40-60^{\circ} \mathrm{C}\right)$ in Soxtec 2050 extraction system (Foss Analytical, Hilleroed, DK). Fatty acid methyl esters were determined according to ISTE method (Park \& Goins 1994). Separation and quantification of fatty acid methyl esters was carried out using a gas chromatograph Agilent 6890 (Agilent Technologies, Santa Clara, CA, USA) fitted with an automatic sampler Agilent 7683 (Agilent Technologies, Santa Clara, CA, USA) and a flame ionization detector. Fatty acid methyl esters were separated on a SP-2560 fused-silica capillary column (100 m $\times 0.25 \mathrm{~mm}$ i.d., $0.2 \mu \mathrm{m}$ film thickness; Supelco Inc., Bellefonte, PA, USA) using a split/splitless injection system and helium as carrier gas at a flow rate of $0.9 \mathrm{ml} / \mathrm{min}$. Separated fatty acid methyl esters were identified using their retention times and quantified using response factors derived from external standards GLC 85, GLC 411 and GLC 68a (Nu-Chek Prep, Inc., Elysian, MN, USA). Results are expressed as a weight percentage (wt \%) of the total identified fatty acids. For each sample 34 fatty acids were evaluated altogether. They were used for the saturated (SFA), monounsaturated (MUFA), polyunsaturated (PUFA), n-3 PUFA, n-6 PUFA and n-6/n-3 PUFA ratio evaluation.

\section{Sensory analysis}

Samples were thawed overnight prior to sensory evaluation. Sensory evaluation was carried out on the samples by six trained panellists of Biotechnical Faculty, Food Science and Technology Department. Two identical ovens were used at a grilling temperature of $200^{\circ} \mathrm{C}$ to cook the meat. Baking trays with grilling racks were placed on the middle shelf position. The meat was cooked by grilling until the internal endpoint temperature was $75^{\circ} \mathrm{C}$. Samples were dissected immediately after cooking, wrapped in aluminium foil and kept in warming ovens (set at $100^{\circ} \mathrm{C}$ ) until serving within 20 min. Sensory evaluation was carried out in a sensory analysis laboratory with individual booths. Sensory evaluation was carried out for 4 consecutive days with two sessions per day. During the session each panellist tasted four different samples serviced on a clean plastic plate each time. Water and fresh apple slices were used as mouth cleansers before tasting and in between tasting samples. The panellists were instructed to take a bite of the apple followed by a sip of water and wait for $30 \mathrm{~s}$ in order to restore the normal environment in the mouth between samples. Samples were coded with sample number and panellist number and the serving sequence was randomised. Before thermal treatment, panellists assessed fresh meat colour (1=extremely bright; $7=$ extremely dark) and marbling (1=extremely low; $7=$ extremely high) of the samples using a sevenpoint scale. After cooking the panellists assessed sensory characteristics of goat meat using a seven-point scale for off-odour (1=extremely bland; $7=$ extremely intense), flavour ( $1=$ extremely undesirable; $7=$ extremely desirable), juiciness ( $1=$ extremely dry; $7=$ extremely juicy) and tenderness (1=extremely tough; $7=$ extremely tender). 


\section{Statistical analysis}

The effects of sex and slaughter weight on fatty acid composition and sensory analysis were analysed using MIXED procedures of SAS/STAT software package v9.2 (SAS Institute Inc., Cary, NC, USA). The analysis was performed according to the following linear model:

$$
y_{i j k}=\mu+S_{i}+G_{j}+(S G)_{i j}+e_{i j k}
$$

where $y_{i j k}$ is the dependent variable, $\mu$ is the overall mean, $S$ is the fixed sex effect ${ }_{i}=$ male, female), $G$ is the fixed group effect ( $=$ group 1, group 2), (SG) is the interaction between sex and group effect and $e_{i j k}$ is the residual error. The interaction between sex and group was analysed and there were no significant differences found for the parameters evaluated in the present study. Therefore, only the fixed sex and group effects are presented and discussed. Differences of least squares means of fatty acid composition and sensory analysis were tested using Scheffe's test. Significance levels between least squares means (LSM) for a particular parameter were assessed at $P<0.05$.

\section{Results and discussion}

Fatty acid composition of LD muscle in male and female Boer kids at two different slaughter weights is presented in Table 1. Predominant fatty acids in LD muscle tissue of Boer kids are oleic (32.0-48.3\%), palmitic (17.7-25.2\%) and stearic (5.0-13.9\%), and account about $72 \%$ of total fatty acids. Results of these fatty acids in the present study are lower than the ones reported by Mahgoub et al. (2002) of Omani Jebel Akhdar goats and Werdi Pratiwi et al. (2006) of Boer and Australian feral goats. Since a change in diet after weaning and the increase of slaughter weight may change significantly the fatty acid profiles (Dhanda et al. 2003, Beserra et al. 2004) these differences may relate primarily to differences in the feeding regimes. Nevertheless, we must also consider breed differences and a wider range of slaughter weights used in the studies.

Sex had significant influence on lauric $(P \leq 0.01)$, myristic $(P \leq 0.01)$, pentadecanoic $(P \leq 0.05)$, oleic $(P \leq 0.001)$, linolenic $(P \leq 0.05)$ and docosapentaenoic $(P \leq 0.01)$ acids. The percentage amounts of lauric ( 0.60 vs. 0.36 ), myristic ( 5.35 vs. 4.09 ), pentadecanoic ( 0.80 vs. 0.63 ), linolenic (1.03 vs. 0.74$)$ and docosapentaenoic ( 0.90 vs. 0.50$)$ acids were significantly higher in male kids than in females. Contrary to males, female kids had only higher percentage amount of oleic acid (38.74 vs. 43.55). Bonvillani et al. (2010) also found significant influence of sex on fatty acid muscle composition, where male kids had significantly higher percentages of capric, lauric and myristic acids and the female kids had higher percentages of stearic and linoleic acids. In the present study the percentages of SFA $(P \leq 0.01)$, MUFA $(P \leq 0.001)$, PUFA $(P \leq 0.05)$ and n-3 PUFA $(P \leq 0.01)$ were significantly affected by sex. Male kids had higher percentage amounts of SFA (44.16 vs. 41.03 ), PUFA (10.90 vs. 9.41) and n-3 PUFA (2.79 vs.1.91) than females. Contrary to males, female kids had higher percentage amounts of MUFA (44.91 vs. 49.53).

Slaughter weight significantly affected the fatty acid muscle profiles of Boer kids. The percentage amounts of lauric (0.69), myristic (5.85) and margaric (0.67) acids in the lighter group of kids were significantly higher than those of lauric (0.69), myristic (5.85) and margaric (0.67) acids determined in the heavier kids. Mahgoub et al. (2002) found significant decrease only in amounts of decanoic and lauric acids of Omani Jebel Akhdar goats slaughtered 
at similar weights as in the present study. Heptadecenoic and oleic acids significantly increased at higher slaughter weights $(P \leq 0.001)$. Lighter kids had $1.26 \%$ of heptadecenoic and $37.66 \%$ of oleic acid, while heavier kids had $1.85 \%$ of heptadecenoic and $44.64 \%$ of oleic acid. Partially, this agrees with the findings of Werdi Pratiwi et al. (2006) who found at higher slaughter weights a significant increase $(P \leq 0.01)$ of oleic and palmitoleic acid. In the present study palmitoleic acid was not significantly different at higher slaughter weights. Furthermore, significant decrease $(P \leq 0.001)$ in the content of PUFA such as linoleic, linolenic, arachidonic and docosapentaenoic at higher slaughter weights was noticed. Lighter kids had $5.72 \%$ of linoleic, $1.18 \%$ of linoleinic, $1.95 \%$ of arachidonic and $1.02 \%$ of docosapentaenoic acids, while heavier kids had $4.27 \%$ of linoleic, $0.58 \%$ of linoleinic, $1.13 \%$ of arachidonic and $0.47 \%$ of docosapentaenoic acids.

Table 1

Fatty acid composition of longissimus dorsi muscle of male and female Boer kids at two different slaughter weights $(\mathrm{LSM} \pm \mathrm{SE})$

\begin{tabular}{|c|c|c|c|c|c|c|}
\hline \multirow[t]{2}{*}{ Fatty acid } & \multicolumn{2}{|c|}{ Sex effect } & \multicolumn{4}{|c|}{ Group effect } \\
\hline & $\begin{array}{c}\text { Male } \\
(\mathrm{n}=17)\end{array}$ & $\begin{array}{l}\text { Female } \\
(\mathrm{n}=15)\end{array}$ & $P$ & $\begin{array}{c}\mathrm{G} 1 \\
(\mathrm{n}=16)\end{array}$ & $\begin{array}{c}G 2 \\
(n=16)\end{array}$ & $P$ \\
\hline $\mathrm{C} 12: 0$ & $0.60 \pm 0.05$ & $0.36 \pm 0.052$ & $* *$ & $0.69 \pm 0.050$ & $0.27 \pm 0.050$ & $* * *$ \\
\hline C14:0 & $5.35 \pm 0.28$ & $4.09 \pm 0.306$ & $* *$ & $5.85 \pm 0.296$ & $3.59 \pm 0.298$ & $* * *$ \\
\hline C15:0 & $0.80 \pm 0.050$ & $0.63 \pm 0.053$ & $*$ & $0.70 \pm 0.052$ & $0.73 \pm 0.052$ & ns \\
\hline C16:0 & $21.88 \pm 0.326$ & $21.54 \pm 0.347$ & $\mathrm{~ns}$ & $22.08 \pm 0.336$ & $21.34 \pm 0.338$ & ns \\
\hline C17:0 & $0.63 \pm 0.033$ & $0.59 \pm 0.035$ & ns & $0.67 \pm 0.034$ & $0.56 \pm 0.034$ & * \\
\hline C18:0 & $0.68 \pm 0.020$ & $0.69 \pm 0.021$ & $\mathrm{~ns}$ & $0.69 \pm 0.021$ & $0.68 \pm 0.021$ & ns \\
\hline C16:1 & $3.38 \pm 0.223$ & $3.41 \pm 0.237$ & ns & $3.14 \pm 0.229$ & $3.64 \pm 0.231$ & ns \\
\hline C17:1 & $1.51 \pm 0.094$ & $1.61 \pm 0.100$ & ns & $1.26 \pm 0.097$ & $1.85 \pm 0.098$ & $* * *$ \\
\hline C18:1 & $38.74 \pm 0.594$ & $43.55 \pm 0.632$ & $* * *$ & $37.66 \pm 0.611$ & $44.64 \pm 0.616$ & $* * *$ \\
\hline$C 18: 2 n-6$ & $5.13 \pm 0.258$ & $4.85 \pm 0.275$ & $\mathrm{~ns}$ & $5.72 \pm 0.266$ & $4.27 \pm 0.268$ & $* * *$ \\
\hline C18:3 n-3 & $1.03 \pm 0.077$ & $0.74 \pm 0.082$ & $*$ & $1.18 \pm 0.080$ & $0.58 \pm 0.080$ & $* * *$ \\
\hline$C 20: 4 n-6$ & $1.68 \pm 0.140$ & $1.41 \pm 0.149$ & $\mathrm{~ns}$ & $1.95 \pm 0.144$ & $1.13 \pm 0.145$ & $* * *$ \\
\hline$C 22: 5 n-3$ & $0.90 \pm 0.067$ & $0.59 \pm 0.072$ & $* *$ & $1.02 \pm 0.069$ & $0.47 \pm 0.070$ & $* * *$ \\
\hline$\Sigma$ SFA & $44.16 \pm 0.622$ & $41.03 \pm 0.663$ & $* *$ & $44.59 \pm 0.640$ & $40.61 \pm 0.645$ & $* * *$ \\
\hline ¿MUFA & $44.91 \pm 0.684$ & $49.53 \pm 0.728$ & $* * *$ & $43.25 \pm 0.703$ & $51.19 \pm 0.709$ & $* * *$ \\
\hline ¿PUFA & $10.90 \pm 0.461$ & $9.41 \pm 0.491$ & $*$ & $12.13 \pm 0.475$ & $8.18 \pm 0.478$ & $* * *$ \\
\hline n-3 PUFA & $2.79 \pm 0.211$ & $1.91 \pm 0.224$ & $* *$ & $3.25 \pm 0.217$ & $1.45 \pm 0.219$ & $* * *$ \\
\hline n-6 PUFA & $7.36 \pm 0.387$ & $6.76 \pm 0.412$ & ns & $8.17 \pm 0.398$ & $5.96 \pm 0.402$ & $* * *$ \\
\hline$n-6 / n-3$ PUFA & $2.64 \pm 0.287$ & $3.54 \pm 0.306$ & ns & $2.74 \pm 0.296$ & $4.11 \pm 0.298$ & $* *$ \\
\hline
\end{tabular}

¿SFA: sum of saturated fatty acids $=\mathrm{C} 12: 0+\mathrm{C} 13: 0+\mathrm{C} 14: 0+\mathrm{C} 15: 0+\mathrm{C} 16: 0+\mathrm{C} 17: 0+\mathrm{C} 18: 0+\mathrm{C} 19: 0+\mathrm{C} 20: 0+\mathrm{C} 22: 0 ; \quad$ IMUFA: sum of monounsaturated fatty acids $=C 13: 1 n-1+C 14: 1 n-5+C 15: 1 n-5+C 16: 1 n-7+C 17: 1 n-7+C 18: 1 n-9+C 19: 1 n-9+C 20: 1$ $\mathrm{n}-12+\mathrm{C} 20: 1 \mathrm{n}-9+\mathrm{C} 24: 1 \mathrm{n}-9 ; \quad$ EPUFA: sum of polyunsaturated fatty acids $=\mathrm{C} 18: 2 \mathrm{n}-6+\mathrm{C} 18: 2 \mathrm{c} 9 \mathrm{t} 11+\mathrm{C} 18: 3 \mathrm{n}-3+\mathrm{C} 18: 3$ $n-6+C 18: 4 n-3+C 20: 2 n-6+C 20: 3 n-3+C 20: 3 n-6+C 20: 4 n-6+C 20: 5 n-3+C 22: 3 n-3+C 22: 4 n-6+C 22: 5 n-3+C 22: 6 n-3 ;$ $n-6 / n-3$ PUFA: ratio of the sum of $n-6$ and $n-3$ polyunsaturated fatty acids $=C 18: 2 n-6+C 18: 3 n-6+C 20: 2 n-6+C 20: 3$ $n-6+C 20: 4 \quad n-6+C 22: 4 \quad n-6 / C 18: 3 n-3+C 18: 4 \quad n-3+C 20: 3 n-3+C 20: 5 n-3+C 22: 3 n-3+C 22: 5 n-3+C 22: 6 n-3, \quad G 1:$ predetermined slaughter weight of $20 \mathrm{~kg}, \mathrm{G} 2$ : predetermined slaughter weight of $30 \mathrm{~kg}$, ns: not significant; ${ }^{*} P \leq 0.05$; ${ }^{*} P \leq 0.01 ; \quad{ }^{* * *} P \leq 0.001$

The percentage amounts of SFA, MUFA and PUFA were 37.4-49.9, 36.4-54.6 and 6.1-16.1, respectively. Higher amounts of MUFA and PUFA, from a human health viewpoint, indicate that Boer kids contain more desirable fatty acids, which according to Rhee (1992) have either a neutral or cholesterol-lowering effect. In our study the minimal n-6/n-3 PUFA ratio was 1.5 
and the maximal 6.4. The average value of $n-6 / n-3$ PUFA ratio was 3.6 which is within the recommended range $(<4)$ for human health (World Health Organization 2003). The average value of $n-6 / n-3$ PUFA ratio was higher than those reported by Talpur et al. (2008) for naturally reared male goat kids of Pateri breed and within that reported by Todaro et al. (2006) for male goat kids of Girgentana breed fed on concentrate. The higher value of the $n-6 / n-3$ ratio in the heavier kids of our study could be due to feeding with concentrate. De Smet et al. (2004) reported that the $n-6 / n-3$ PUFA ratios are mainly affected by animal feeds. The possible reason for different $n-6 / n-3$ ratio between mentioned studies could be also because of the difference in calculating the ratio. Todaro et al. (2006) and Talpur et al. (2008) calculated the ratio only from the presented fatty acids and in the present study the ratio was calculated from the whole sample.

Contrary to results of the present study, Bonvillani et al. (2010) found no significant influence of slaughter weight on the main fatty acid percentages. As expected, muscles from lighter kids contained more SFA (44.59\%) compared to kids slaughtered at heavier weights (40.61\%). This could be because younger kids were still suckling, and at this stage the fatty acid composition of their muscle is still dependent on the fatty acid composition of the consumed milk (Pratiwi et al. 2004, Ribeiro et al. 2011). Due to the higher percentage of oleic acid in muscles at heavier slaughter weights, the percentages of unsaturated fatty acids (UFA) and MUFA significantly increased $(P \leq 0.001)$ and were higher than SFA (Table 1). Werdi Pratiwi et al. (2006) also presented data which indicate that muscles at higher slaughter weights had higher percentages of UFA and MUFA, and compared to them, a lower percentage of SFA. The percentages of n-3 PUFA and n- 6 PUFA in our study significantly decreased at higher slaughter weights $(P \leq 0.001)$. Lighter kids contained $3.25 \%$ of $n-3$ PUFA and $8.17 \%$ of $n-6$ PUFA, while heavier kids contained $1.45 \%$ of $n-3$ PUFA and $5.96 \%$ of $n-6$ PUFA. Consequently, $n-6 / n-3$ PUFA ratio at higher slaughter weights significantly increased $(P \leq 0.01)$. The $n-6 / n-3$ PUFA ratio in lighter kids was 2.74 , while in heavier ones was 4.11 . This result could be primarily due to the concentrate diet of heavier kids which increased n-6/n-3 PUFA ratio. Enser et al. (1998) reported that finishing ruminants on pasture can decrease the $n-6 / n-3$ PUFA ratio to a value of two or less, while concentrate-fed ruminants gave ratios around 6-10. Ryan et al. (2007) also found that LD samples from range-fed Boer crossbreed goats had significantly lower n-6/n-3 PUFA ratio than LD samples from concentrate-fed goats.

Sensory panel scores of LD muscle in male and female Boer kids at two different slaughter weights are presented in Table 2. Except for meat colour, sex and slaughter weight did not show significant influence on the analysed sensory traits. Meat quality and acceptability is determined by its physicochemical characteristics, especially its colour as the most important deciding factor for consumers at purchase, and fat composition (Tejeda et al. 2008, Nassu et al. 2012). Beside that, LSU AgCenter (2010) reported that goat meat consumers have indicated a preference for meat with lighter colour. In our study male kids had significantly darker meat colour (4.04) than female kids (4.97) with estimated difference higher for 0.9 units $(P \leq 0.001)$. Although sex affected meat colour, these differences were not high. The effect of sex on the sensory traits is not clear yet. In agreement with results of the present study, Germano Costa et al. (2008), Madruga et al. (2008) and Bonvillani et al. (2010) did not find the effect of sex on the sensory traits, and contrary to them Dawkins et al. (2000) and Rodrigues \& Teixeira (2009) did find it. 
Table 2

Sensory traits of longissimus dorsi muscle of male and female Boer kids at two different slaughter weights $(\mathrm{LSM} \pm \mathrm{SE})$

\begin{tabular}{lcccccc}
\hline Sensory traits & \multicolumn{2}{c}{ Sex effect } & \multicolumn{3}{c}{ Group effect } \\
& $\begin{array}{l}\text { Male } \\
(\mathrm{n}=17)\end{array}$ & $\begin{array}{c}\text { Female } \\
(\mathrm{n}=15)\end{array}$ & $\mathrm{P}$ & $\begin{array}{c}\mathrm{G} 1^{1} \\
(\mathrm{n}=16)\end{array}$ & $\begin{array}{c}\mathrm{G} 2^{1} \\
(\mathrm{n}=16)\end{array}$ & $\mathrm{P}$ \\
\hline Meat colour & $4.04 \pm 0.165$ & $4.97 \pm 0.175$ & $* * *$ & $4.24 \pm 0.169$ & $4.77 \pm 0.171$ & $*$ \\
Marbling & $1.56 \pm 0.087$ & $1.73 \pm 0.093$ & $\mathrm{~ns}$ & $1.53 \pm 0.090$ & $1.75 \pm 0.091$ & $\mathrm{~ns}$ \\
Off-odour & $1.44 \pm 0.128$ & $1.70 \pm 0.136$ & $\mathrm{~ns}$ & $1.56 \pm 0.131$ & $1.57 \pm 0.132$ & $\mathrm{~ns}$ \\
Flavour & $5.53 \pm 0.058$ & $5.50 \pm 0.062$ & $\mathrm{~ns}$ & $5.50 \pm 0.060$ & $5.53 \pm 0.060$ & $\mathrm{~ns}$ \\
Juiciness & $5.53 \pm 0.065$ & $5.37 \pm 0.069$ & $\mathrm{~ns}$ & $5.46 \pm 0.067$ & $5.43 \pm 0.068$ & $\mathrm{~ns}$ \\
Tenderness & $4.93 \pm 0.137$ & $4.78 \pm 0.146$ & $\mathrm{~ns}$ & $4.85 \pm 0.141$ & $4.87 \pm 0.142$ & $\mathrm{~ns}$ \\
\hline
\end{tabular}

G1: predetermined slaughter weight of $20 \mathrm{~kg}, \mathrm{G} 2$ : predetermined slaughter weight of $30 \mathrm{~kg}$, ns: not significant, ${ }^{*} P \leq 0.05, \quad{ }^{* *} P \leq 0.001$

Heavier kids had significantly darker meat colour (4.77) than the lighter ones (4.24) with estimated difference for 0.5 units $(P \leq 0.05)$.The meat colour score in the present study tends to increase as slaughter weight increases, as expected because as maturity increases, muscle colour becomes darker in goats (Peña et al. 2009). This is similar to the results reported by Pratiwi et al. (2004), where muscle redness ( $a^{*}$ values) and subjective muscle scores (1: pale red, 9: dark red) were positively correlated with muscle pigment concentrations, meaning that muscle colour from heavier Boer bucks was darker. Dhanda et al. (1999) also reported darker meat of chevon (slaughter weight in range of $30-35 \mathrm{~kg}$ ) in comparison to capretto meat (slaughter weight in range $14-22 \mathrm{~kg}$ ).

In the present study no significant effect of slaughter weight on flavour, juiciness or tenderness of cooked meat was detected. Dhanda et al. (2003) found similar results with no significant effect of age/body weight on flavour, juiciness and tenderness between capretto and chevon meat at comparable slaughter weights. Schönfeldt et al. (1993) reported that there was no indication of any off flavour or odour from cooked goat meat. This appears contradictory to the concept that the meat from heavier and older goats has a strong unattractive flavour. The main reason for such results in the present study could be due the smaller difference between experimental slaughter weights of the groups.

It can be concluded that male and female Boer kids, across the range of $20-30 \mathrm{~kg}$ of slaughter weight, produced meat of different fatty acid composition with no difference in juiciness, tenderness and flavour. Slaughtering of Boer kids at $30 \mathrm{~kg}$ could be recommended as increased the goat meat production with still good meat quality. As sensory evaluation of goat meat has relatively limited research, we recommend that in the future, as goat meat is gaining popularity, it is necessary to conduct more detailed studies with consumers included.

\section{References}

Beserra FJ, Madruga MS, Leite AM, da Silva EMC, Maia EL (2004) Effect of age at slaughter on chemical composition of meat from Moxotó goats and their crosses. Small Rumin Res 55, 177-181

Bonvillani A, Peña F, Domenech V, Polvillo O, García PT, Casal JJ (2010) Meat quality of Criollo Cordobes goat kids produced under extensive feeding conditions. Effects of sex and age/weight at slaughter. Span J Agric Res 8, 116-125 
Dawkins NL, McMillin KW, Phelps O, Gebrelul S, Beyer AJ, Howard A (2000) Palatability studies as influenced by consumer demographics and chevon characteristics. J Muscle Foods 11, 45-59

De Smet S (2012) Meat, poultry, and fish composition: Strategies for optimizing human intake of essential nutrients. Anim Front 2, 10-16

De Smet S, Raes K, Demeyer D (2004) Meat fatty acid composition as affected by fatness and genetic factors: a review. Anim Res 53, 81-98

Dhanda JS, Taylor DG, Murray PJ (2003) Part 2. Carcass composition and fatty acid profiles of adipose tissue of male goats: effects of genotype and liveweight at slaughter. Small Rumin Res 50, 67-74

Dhanda JS, Taylor DG, Murray PJ, McCosker JE (1999) The influence of goat genotype on the production of Capretto and Chevon carcasses. 2. Meat quality. Meat Sci 52, 363-367

Enser M, Hallett kg, Hewett B, Fursey GAJ, Wood JD, Harrington G (1998) Fatty acid content and composition of $\mathrm{UK}$ beef and lamb muscle in relation to production system and implications for human nutrition. Meat Sci 49, 329-341

Fisher AV, Enser M, Richardson RI, Wood JD, Nute GR, Kurt E, Sinclair LA, Wilkinson RG (2000) Fatty acid composition and eating quality of lamb types derived from four diverse breed $x$ production systems. Meat Sci 55, 141-147

Germano Costa R, Galán H, Camacho Vallejo ME, Vallecillo A, Delgado Bermejo JV, Argüello Henríquez A (2008) [Sensorial characteristics of the Blanca Serrana Andaluza goat meat ]. Arch Zoot 57, 67-70 [in Spanish]

Kor A, Keskin S (2011) Quality and Sensory Evaluation for Goat Meat Using Generalized Procrustes Analysis. J Anim Vet Adv 10, 1313-1316

Krystallis A, Arvanitoyannis IS (2006) Investigating the concept of meat quality from the consumers' perspective: The case of Greece. Meat Sci 72, 164-176

LSU AgCenter (2010) Meat Goat Selection, Carcass Evaluation \& Fabrication Guide. Lousiana State University, Agricultural Center, Baton Rouge, LA, USA, http://www.Isuagcenter.com/en/communications/publications/ Publications+Catalog/Crops+and+Livestock/Goats/Meat+Goat+Selection+Carcass+Evaulation+and +Fabrication.htm [last accessed 17.03.2013]

Madruga MS (2004) [Chemical quality. Sensory and aroma of goat meat: myths and truths]. In: Periódicos AE (ed.) VIII Encontro Nacional para o Desenvolvimento da Espécie Caprina. Universidade Estadual Paulista, Botucatu, Brazil, 215-234 [in Portuguese]

Madruga MS, Torres TS, Carvalho FF, Queiroga RC, Narain N, Garruti D, Souza Neto MA, Mattos CW, Costa RG (2008) Meat quality of Moxotó and Canindé goats as affected by two levels of feeding. Meat Sci 80, 10191023

Mahgoub O, Khan AJ, AI-Maqbaly RS, Al-Sabahi JN, Annamalai K, AI-Sakry NM (2002) Fatty acid composition of muscle and fat tissues of Omani Jebel Akhdar goats of different sexes and weights. Meat Sci 61, 381-387

Nassu RT, Uttaro B, Aalhus JL, Zawadski S, Juárez M, Dugan MER (2012) Type of packaging affects the colour stability of vitamin E enriched beef. Food Chem 135, 1868-1872

Park PW, Goins RE (1994) In Situ Preparation of Fatty Acid Methyl Esters for Analysis of Fatty Acid Composition in Foods. J Food Sci 59, 1262-1266

Peña F, Bonvillani A, Freire B, Juárez M, Perea J, Gómez G (2009) Effects of genotype and slaughter weight on the meat quality of Criollo Cordobes and Anglonubian kids produced under extensive feeding conditions. Meat Sci 83, 417-422

Rhee KS (1992) Fatty acids in meats and meat products. In: Chow CK (ed.) Fatty acids in foods and their health implications. Marcel Dekker Inc., New York, USA, 65-93

Ribeiro CVM, de Oliveira DE, Juchem SO, Silva TM, Nalério ÉS (2011) Fatty acid profile of meat and milk from small ruminants: a review. R Bras Zootec 40 (Suppl.), 121-137

Rodrigues S, Teixeira A (2009) Effect of sex and carcass weight of sensory quality of goat meat of Cabrito Transmontano. J Anim Sci 87, 711-715

Ryan SM, Unruh JA, Corrigan ME, Drouillard JS, Seyfert M (2007) Effects of concentrate level on carcass traits of Boer crossbred goats. Small Rumin Res 73, 67-76 
Schönfeldt HC, Naudé RT, Bok RT, van Heerden SM, Smit R, Boshoff E, (1993) Flavour- and tenderness-related quality characteristics of goat and sheep meat. Meat Sci 34, 363-379

Talpur FN, Bhanger MI, Sherazi STH (2008) Intramuscular fatty acid profile of longissimus dorsi and semitendinosus muscle from Pateri goats fed under traditional feeding system of Sindh, Pakistan. Meat Sci 80, 819-822

Tejeda JF, Peña RE, Andrés Al (2008) Effect of live weight and sex on physico-chemical and sensorial characteristics of Merino lamb meat. Meat Sci 80, 1061-1067

Todaro M, Corrao A, Barone CMA, Alicata ML, Schinelli R, Giaccone P (2006) Use of weaning concentrate in the feeding of suckling kids: Effects on meat quality. Small Rumin Res 66, 44-50

Werdi Pratiwi NMW, Murray PJ, Taylor DG (2004) Meat quality of entire and castrated male Boer goats raised under Australian conditions and slaughtered at different weights: physical characteristics, shear force values and eating quality profiles. Anim Sci 79, 213-219

Werdi Pratiwi NM, Murray PJ, Taylor DG, Zhang D (2006) Comparison of breed, slaughter weight and castration on fatty acid profiles in the longissimus thoracic muscle from male Boer and Australian feral goats. Small Rumin Res 64, 94-100

World Health Organization (2003) Diet, nutrition and the prevention of chronic diseases: report of a joint WHO/FAO expert consultation. WHO technical report series no. 916, Geneva, Switzerland 